\title{
THE PREVALENCE OF DEPRESSION SYMPTOMS AMONG ADVANCED BREAST CANCER PATIENTS: A SYSTEMATIC REVIEW AND META-ANALYSIS
}

\author{
Indira KARIBAYEVA ${ }^{1 凶}$, Botagoz TURDALIYEVA ${ }^{1}$, Nor Zuraida ZAINAL ${ }^{2}$, \\ Fatima BAGIYAROVA ${ }^{3}$
}

${ }^{1}$ Department of Public Health, Kazakh Medical University of Continuing Education, Almaty, Kazakhstan

${ }^{2}$ Department of Psychological Medicine, Faculty of Medicine, University of Malaya, Kuala Lumpur, Malaysia

${ }^{3}$ Department of Communication Skills, Asfendiyarov Kazakh National Medical University, Almaty, Kazakhstan

Received 30 Oct 2020, Accepted 21 Nov 2020

hitps://doi.org/10.31688/ABMU.2020.55.4.12

\section{Abstract}

Introduction. Depression in patients with advanced breast cancer is a serious comorbidity that affects the quality of life of these patients, and their survival rates. Objective. This study aims at systematically reviewing the current literature with data on the prevalence of depression symptoms in metastatic and recurrent breast cancer patients, examining the pooled mean prevalence of depression symptoms and potential sources of heterogeneity.

Methods. An extensive systematic review of PubMed, Web of Science, Scopus, ScienceDirect, Google Scholar, American Doctoral Dissertations and Open Grey databases, and the following reference list hand-search was performed to retrieve studies from January 2005.

Results. We identified 11 eligible studies that assessed 1223 patients on the presence of depression symptoms, and 465 patients met the criteria. According to the random-effects model, the pooled mean prevalence of depression was 38.23\% (95\% CI [30.92; 45.83]; I2=

\section{Résumé}

La prévalence des symptômes de dépression chez les patientes atteintes d'un cancer du sein en stade avancé : revue systématique et méta-analyse

Introduction. La dépression chez les patientes atteintes d'un cancer du sein avancé est une comorbidité grave qui affecte la qualité de vie des patientes et leur taux de survie.

Objectif. Cette étude vise à examiner systématiquement la littérature actuelle avec des données sur la prévalence des symptômes de dépression chez les patientes atteintes d'un cancer du sein métastatique et récurrent, à examiner la prévalence moyenne combinée des symptômes de dépression et les sources potentielles d'hétérogénéité.

Méthodes. Une revue systématique approfondie des bases de données PubMed, Web of Science, Scopus, ScienceDirect, Google Scholar, American Doctoral Dissertations et Open Gray, ainsi que la recherche manuelle de la liste de référence suivante ont été 
87\%; $\mathrm{Q}(\mathrm{df}=10)=77.89$, p-value < 0.01). Patients with metastatic stage had a slightly higher prevalence of depression symptoms compared to recurrent breast cancer patients.

Conclusion. Prevalence of depression symptoms among advanced breast cancer patients is high. It is important to improve psychological prevention methods to decrease the occurrence of depression, as breast cancer patients start receiving care from primary diagnosis and offer continuous support and treatment to meet their psychological needs.

Keywords: breast cancer, depression, metastatic, meta-analysis, recurrent, systematic review.

\section{Abbreviations}

BDI = Beck Depression Inventory

CES-D = Center for Epidemiologic Studies Depression scale

HADS $=$ Hospital Anxiety and Depression Scale

$\mathrm{PECO}=$ population, exposure, comparator, and outcome

PRISMA = Preferred Reporting Items for Systematic Reviews and Meta-Analyses

$\mathrm{QAC}=$ Quality Assessment Checklist

SDS $=$ Zung Self-Rating Scale for Depression .

\section{INTRODUCTION}

Breast cancer is one of the most prevalent cancer types affecting women worldwide, and in 2018, $12.3 \%$ of all diagnosed cancer cases globally were attributed to breast cancer ${ }^{1}$. According to a meta-analysis of the global survival rates of women with breast cancer, the 5-year pooled survival rate is $73 \%$ (95\% CI [71-75]), and 10-year global pooled survival rate is $61 \%(95 \% \mathrm{CI}[54-67])^{2}$. Colleoni and colleagues (2016) found that $10.4 \%$ of patients with local and regional breast cancer are at risk of cancer recurrence after initial treatment during the first five years of being disease-free ${ }^{3}$. According to several prospective studies, the recurrence rate could go up to $40 \%$ in some patients' population, and it could take up to 15 years to return $n^{4,5,6}$. The site of recurrence for breast cancer could be local, regional or distant ${ }^{3}$. Patients with cancer recurrence, especially with a distant recurrence, experience physical and psychological impairments across multiple domains of quality of life indicators ${ }^{7,8}$.

Patients with recurrent and de novo metastatic breast cancer are considered advanced cancer patients, with poorer prognosis of survival $1^{9}$. According to the American Cancer Society, the 5-year survival of metastatic breast cancer patients is $27 \%{ }^{10}$. Having effectuées pour récupérer des études à partir de janvier 2005.

Résultats. Nous avons identifié 11 études éligibles qui évaluaient 1223 patientes sur la présence de symptômes de dépression, et 465 patientes répondaient aux critères. Selon le modèle à effets aléatoires, la prévalence moyenne combinée de la dépression était de $38,23 \%$ (IC à $95 \%$ [30,92; 45,83]; I2 = 87\%; Q $(\mathrm{df}=10)$ $=77,89$, p-value $<0,01)$. Les patientes au stade métastatique avaient une prévalence légèrement plus élevée des symptômes de dépression par rapport aux patientes atteintes d'un cancer du sein récurrent.

Conclusion. La prévalence des symptômes de dépression chez les patientes atteintes d'un cancer du sein avancé est élevée. Il est important d'améliorer les méthodes de prévention psychologique pour réduire la survenue de la dépression, car les patientes atteintes d'un cancer du sein commencent à recevoir des soins dès le diagnostic primaire et offrir un soutien et un traitement continus pour répondre à leurs besoins psychologiques.

Mots-clés: cancer du sein, dépression, métastatique, méta-analyse, récurrente, revue systématique.

a progressive illness that could significantly limit the longevity imposes a high psychological burden on patients ${ }^{11}$. Depression in patients with breast cancer, and especially in metastatic and recurrent breast cancer patients is a serious comorbidity that could not only affect the quality of life for patients but most importantly, further lower their survival rates ${ }^{12}$. Furthermore, among hospitalized female cancer patients with metastatic disease higher number of comorbidities were associated with diagnosed depression ${ }^{13}$.

To the authors' best knowledge, a systematic review of the prevalence of depression symptoms among metastatic and recurrent breast cancer patients has not been performed.

The OBJeCtIVE OF THE STUDY was to systematically review current literature with data on the prevalence of depression symptoms in metastatic and recurrent breast cancer patients, examine the pooled mean prevalence of depression symptoms and potential sources of heterogeneity.

\section{Material AND MEthods}

The study protocol is registered with the PROSPERO International prospective register of systematic reviews (Reference: CRD42020153960). 


\section{Search strategy}

For this review, PubMed, Web of Science, Scopus, ScienceDirect, Google Scholar, American Doctoral Dissertations and Open Grey databases were searched with the last search being done in July 2020. Search terms were based on the population, exposure, comparator, and outcome (PECO) of interest (population: breast cancer, comparator: none, exposure: prevalence numbers, outcome: depression symptoms). The full search strategy is presented as Appendix 1. Initially, eleven studies were selected from the database search, and then we performed hand search based on the list of references of the selected articles. The PROSPERO database was also searched to identify the registration of similar studies.

\section{Eligibility criteria}

In this review, we used methods from the Preferred Reporting Items for Systematic Reviews and Meta-Analyses (PRISMA). The inclusion criteria for the studies: 1) adults (aged 218 ); 2) metastatic (stage IV) or recurrent (local, regional, or distant) breast cancer patients with a primary diagnosis of breast cancer; 3) reported either proportion or number of patients with depression symptoms using self-report evaluation tools; 4) were observational 5) published in English since 2005. The exclusion criteria: 1) publications that did not convey study results; 2) publications that duplicated previously reported study results; 3 ) publications that focused only on young or geriatric patients; 4) had a high risk of bias; 5) lacked required information.

\section{Selection of studies and data extraction}

Following the PRISMA guidelines, the database search, and the selection of studies based on their eligibility and data extraction were performed by two independent researches (IK and FB) ${ }^{14}$. Up to two contacts via email were made to authors to obtain missing data. The required information list was created and approved by all authors, and included: first author, year of publication, country, study design, sampling, number of eligible and approached patients, number of included patients, age, marital status, depression evaluation scale, evaluation scale cutoff, number of patients with depression symptoms and risk of bias.

\section{Quality assessment}

To assess the risk of bias, we used the nine-item Quality Assessment Checklist (QAC) for prevalence studies $^{15}$. The QAC evaluates the representativeness of the target population, the representativeness of the sample, the selection bias, the non-response bias, the data collection method, the case definition acceptability, the assessment tool reliability and validity, the mode of data collection, and the calculation adequateness. Each item is scored "0" if the risk of bias is absent, and "1" if present. The overall risk of bias is calculated as the summation of all points. The risk of bias is low if the sum of points is between 0 and 3 . Each researcher evaluated the risk of bias independently for every included article, and disagreements, when present, were resolved through consensus.

\section{Data analysis}

Data analysis was performed using R-studio statistical software with the meta- and metaphor- packages. To account for some level of between-study variability and identify potential influential studies for the meta-analysis results we performed a leave-one-out analysis. The outcome of interest was the number of patients with depression symptoms, according to the results of a self-report depression questionnaire. Data were combined using a forest plot. The pooled average prevalence of depression symptoms was calculated with Freeman-Tukey double arcsine transformation using random-effects restricted maximum likelihood estimator to handle small sample sizes and extreme proportions. To examine whether clinical and sociodemographic factors account for the heterogeneity in the prevalence of depression symptoms among metastatic and recurrent breast cancer patients, we performed the univariable meta-regression analysis. To further explore the sources of heterogeneity, several subgroup analyses were performed. For the subgroup analysis, because of the different sample sizes, we assumed a common between-study variance component and pooled within-group estimates of between-study variance.

\section{Assessment of risk of bias across studies}

To detect the risk of publication bias that may affect the cumulative evidence, we plotted the proportion of patients with depression symptoms in each included study by the inverse of its standard error, and then visually examined the funnel plot on the presence of the asymmetry. To examine, if the method of funnel plot construction can induce the asymmetry, we plotted the proportion of patients with depression symptoms by the inverse of the sample size in each study. As a next step of assessment, we performed the Egger's unweighted regression test for funnel plot asymmetry.

\section{Results}

The extensive search of PubMed, Web of Science, Scopus, ScienceDirect, Google Scholar, American Doctoral Dissertations and Open Grey 
PRISMA 2009 Flow Diagram
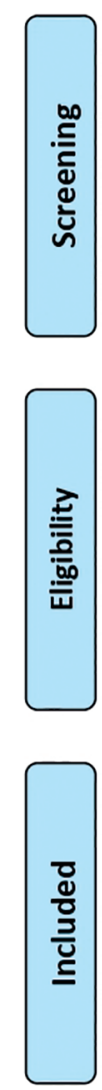

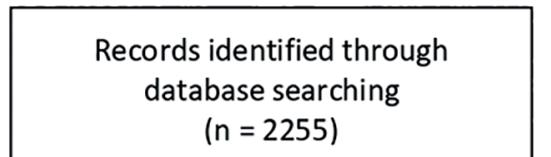

$(n=2255)$
Additional records identified through other sources $(n=509)$

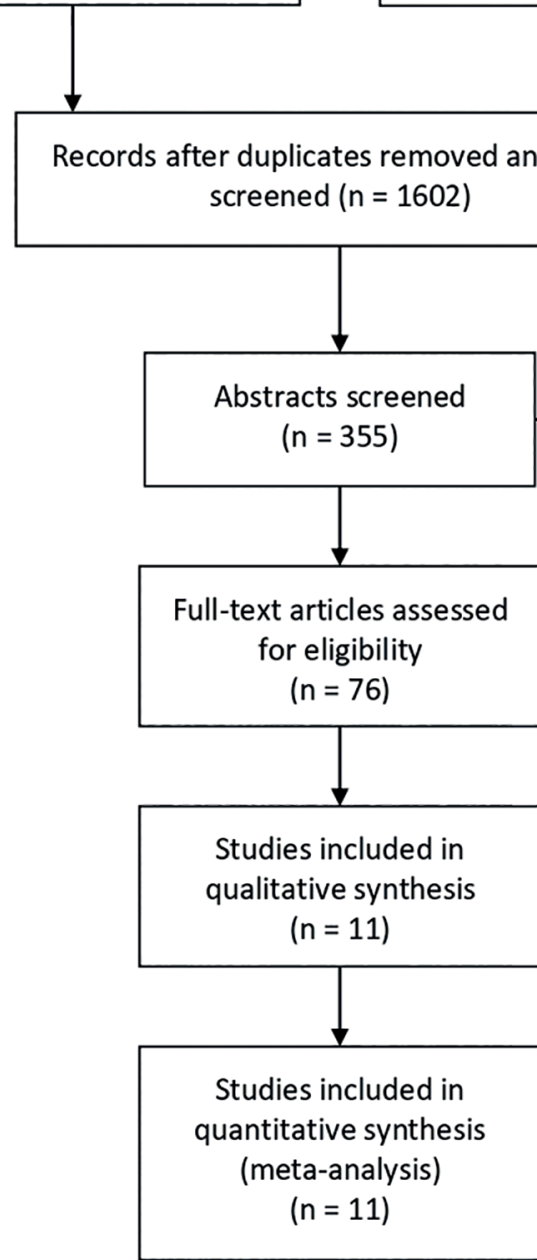

Fig. 1. The PRISMA flowchart of study selection.

databases retrieved 1602 non-duplicative articles. 76 papers were screened for their eligibility, and eleven studies met the criteria. The initial reference search included 509 references of those eleven articles, where no additional articles met the inclusion criteria (Fig. 1).

\section{Characteristics of included studies}

The proportion or number of patients with depression symptoms were reported in eleven studies, that were conducted in seven countries using four different diagnostic methods, such as Beck Depression Inventory (BDI), Center for Epidemiologic Studies Depression scale (CES-D), Hospital Anxiety and Depression Scale (HADS) and Zung Self-Rating Scale for Depression (SDS). The sample size ranged from 41 to 201 participants, with a mean sample size of 111 . The mean age of participants was 56.83 years (range: 51-65 years). Most of the studies had cross-sectional design, and consecutive sampling method. All included studies had a low risk of bias and scored three or below on the QAC scale. 
Table 1. Characteristics of the included studies.

\begin{tabular}{|c|c|c|c|c|c|c|c|c|c|c|c|c|}
\hline \# & First author & Year & Country & $\begin{array}{c}\text { Income } \\
\text { level }\end{array}$ & $\begin{array}{l}\text { Hoy } \\
\text { score }\end{array}$ & Design & $\begin{array}{l}\text { Sam- } \\
\text { pling }\end{array}$ & $\begin{array}{l}\text { Sample } \\
\text { size }\end{array}$ & $\begin{array}{c}\text { Depressed } \\
\text { pts } n(\%)\end{array}$ & $\begin{array}{c}\text { Depression } \\
\text { scale }\end{array}$ & $\begin{array}{l}\text { Age, years } \\
\text { mean (SD) }\end{array}$ & $\begin{array}{c}\text { Married } \\
n(\%)\end{array}$ \\
\hline 1 & $\begin{array}{l}\text { Alfano } \\
\text { A.C. }{ }^{36}\end{array}$ & 2013 & Brazil & $\begin{array}{c}\text { up- } \\
\text { per-mid- } \\
\text { dle }\end{array}$ & 3 & $\begin{array}{l}\text { cross-sec- } \\
\text { tional }\end{array}$ & $\begin{array}{l}\text { consecu- } \\
\text { tive }\end{array}$ & 126 & $47(37.3)$ & HADS (8) & $51,4(10.9)$ & $74(58.7)$ \\
\hline 2 & $\begin{array}{c}\text { Brothers } \\
\text { B.M. }{ }^{37}\end{array}$ & 2009 & USA & high & & cohort & $\begin{array}{l}\text { consecu- } \\
\text { tive }\end{array}$ & 67 & $24(35.8)$ & CES-D (16) & $54(11)$ & \\
\hline 3 & Guo X..$^{17}$ & 2017 & China & $\begin{array}{l}\text { up- } \\
\text { per-mid- } \\
\text { dle }\end{array}$ & 3 & cohort & $\begin{array}{l}\text { consecu- } \\
\text { tive }\end{array}$ & 176 & $104(59.1)$ & $\operatorname{SDS}(50)$ & & \\
\hline 4 & Jehn C.F. ${ }^{37}$ & 2012 & Germany & high & 3 & $\begin{array}{c}\text { cross-sec- } \\
\text { tional }\end{array}$ & $\begin{array}{l}\text { consecu- } \\
\text { tive }\end{array}$ & 70 & $29(41.4)$ & HADS (8) & $59,9(10.2)$ & \\
\hline 5 & $\begin{array}{l}\text { Keurogh- } \\
\text { lian A.S. }{ }^{38} \\
\end{array}$ & 2010 & USA & high & 3 & $\begin{array}{c}\text { cross-sec- } \\
\text { tional }\end{array}$ & $\begin{array}{l}\text { consecu- } \\
\text { tive }\end{array}$ & 124 & $32(25.8)$ & CES-D (16) & $53,1(10.6)$ & $\begin{array}{c}70 \\
(56.45) \\
\end{array}$ \\
\hline 6 & $\begin{array}{c}\text { Kokkonen } \\
\text { K. }^{39} \\
\end{array}$ & 2017 & Finland & high & 3 & $\begin{array}{c}\text { cross } \\
\text { sectional }\end{array}$ & $\begin{array}{l}\text { consecu- } \\
\text { tive }\end{array}$ & 119 & $44(37.0)$ & BDI (5) & & \\
\hline 7 & Low C.A. ${ }^{40}$ & 2015 & USA & high & 4 & cohort & $\begin{array}{l}\text { consecu- } \\
\text { tive }\end{array}$ & 103 & $40(38.8)$ & CES-D (16) & $57,2(10.84)$ & $69(67)$ \\
\hline 8 & Milbury K. ${ }^{41}$ & 2013 & USA & high & 3 & $\begin{array}{c}\text { cross } \\
\text { sectional }\end{array}$ & $\begin{array}{l}\text { consecu- } \\
\text { tive }\end{array}$ & 201 & $74(36.8)$ & CES-D (16) & $52,2(10.5)$ & 199 (99) \\
\hline 9 & $\begin{array}{c}\text { Sarenmalm } \\
\text { E.K. }{ }^{42}\end{array}$ & 2007 & Sweden & high & 3 & $\begin{array}{l}\text { descrip- } \\
\text { tive }\end{array}$ & $\begin{array}{l}\text { consecu- } \\
\text { tive }\end{array}$ & 56 & $21(37.5)$ & HADS (8) & 65 & $35(62.5)$ \\
\hline 10 & Shin J.A. ${ }^{16}$ & 2016 & USA & high & & $\begin{array}{c}\text { cross-sec- } \\
\text { tional }\end{array}$ & $\begin{array}{l}\text { consecu- } \\
\text { tive }\end{array}$ & 140 & 25 (17.9) & HADS (7) & $60,71(12.8)$ & $\begin{array}{c}83 \\
(59.29) \\
\end{array}$ \\
\hline 11 & $\begin{array}{l}\text { Slovacek } \\
\text { L. }^{43}\end{array}$ & 2009 & Czech & high & 3 & $\begin{array}{c}\text { cross } \\
\text { sectional }\end{array}$ & $\begin{array}{l}\text { consecu- } \\
\text { tive }\end{array}$ & 41 & $25(61)$ & $\operatorname{SDS}(50)$ & 58 & \\
\hline
\end{tabular}

Abbreviations: BDI, Beck Depression Inventory; CES-D, Center for Epidemiologic Studies Depression Scale; HADS, Hospital Anxiety and Depression Scale; n, number; pts, patients; SD, standard deviation; SDS, Zung Self-Rating Scale for Depression; USA, the United States of America.

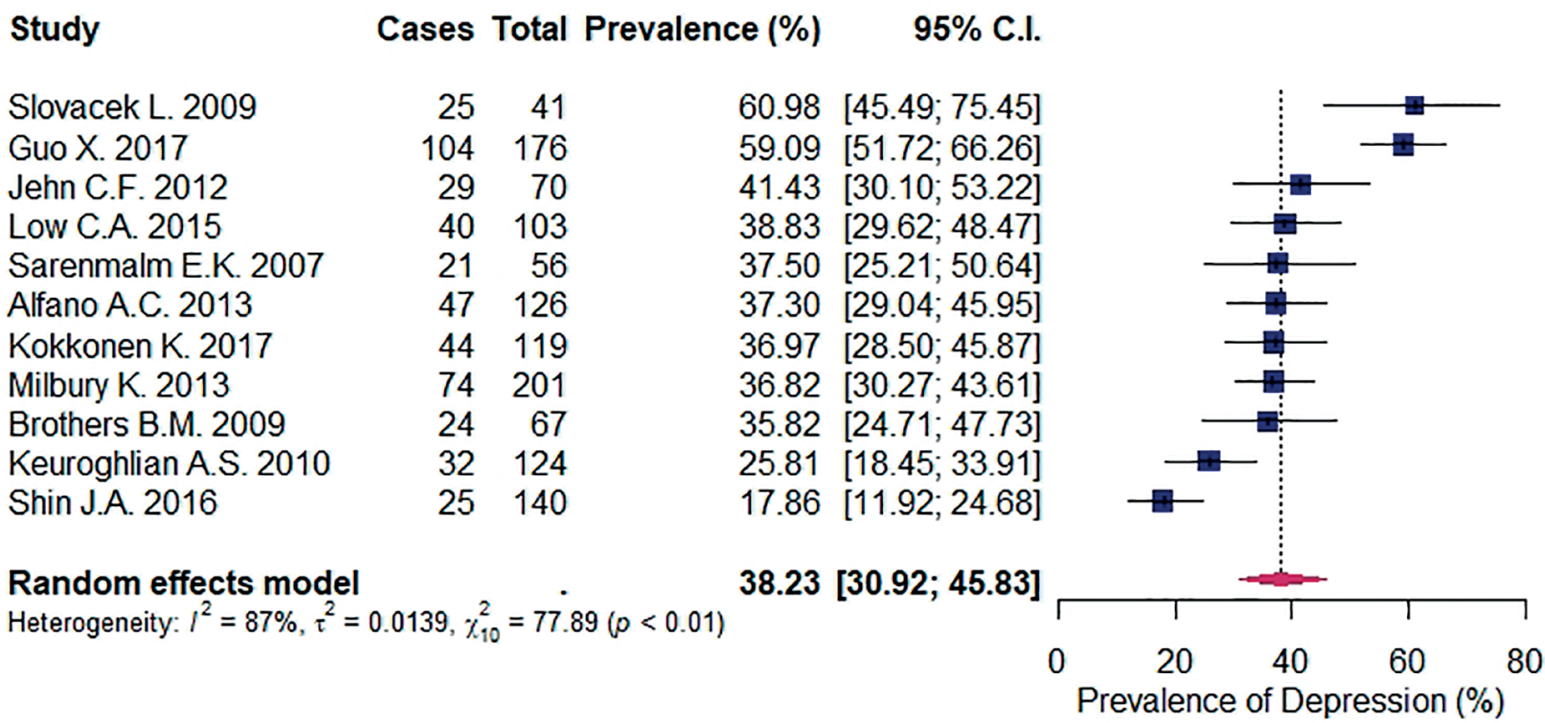

Fig. 2. Prevalence of depression symptoms based on the random-effects model among advanced breast cancer patients. Abbreviations: C.I., confidence interval; $I^{2}$, percentage of variability in the effect sizes which is not caused by sampling error; $\tau^{2}$, between-study variance in the meta-analysis; $\chi 2$, (Q-statistic) difference between the observed effect sizes and the fixed-effect model estimate of the effect size.

1403 patients were eligible and approached, and 1223 (87.17\%) patients agreed to participate in eleven prevalence studies. In total, symptoms of clinically significant depression were diagnosed in 465 out of 1223 patients (Table 1 ). 


Study $\quad$ Prevalence (\%) $\quad 95 \%$ C.I.

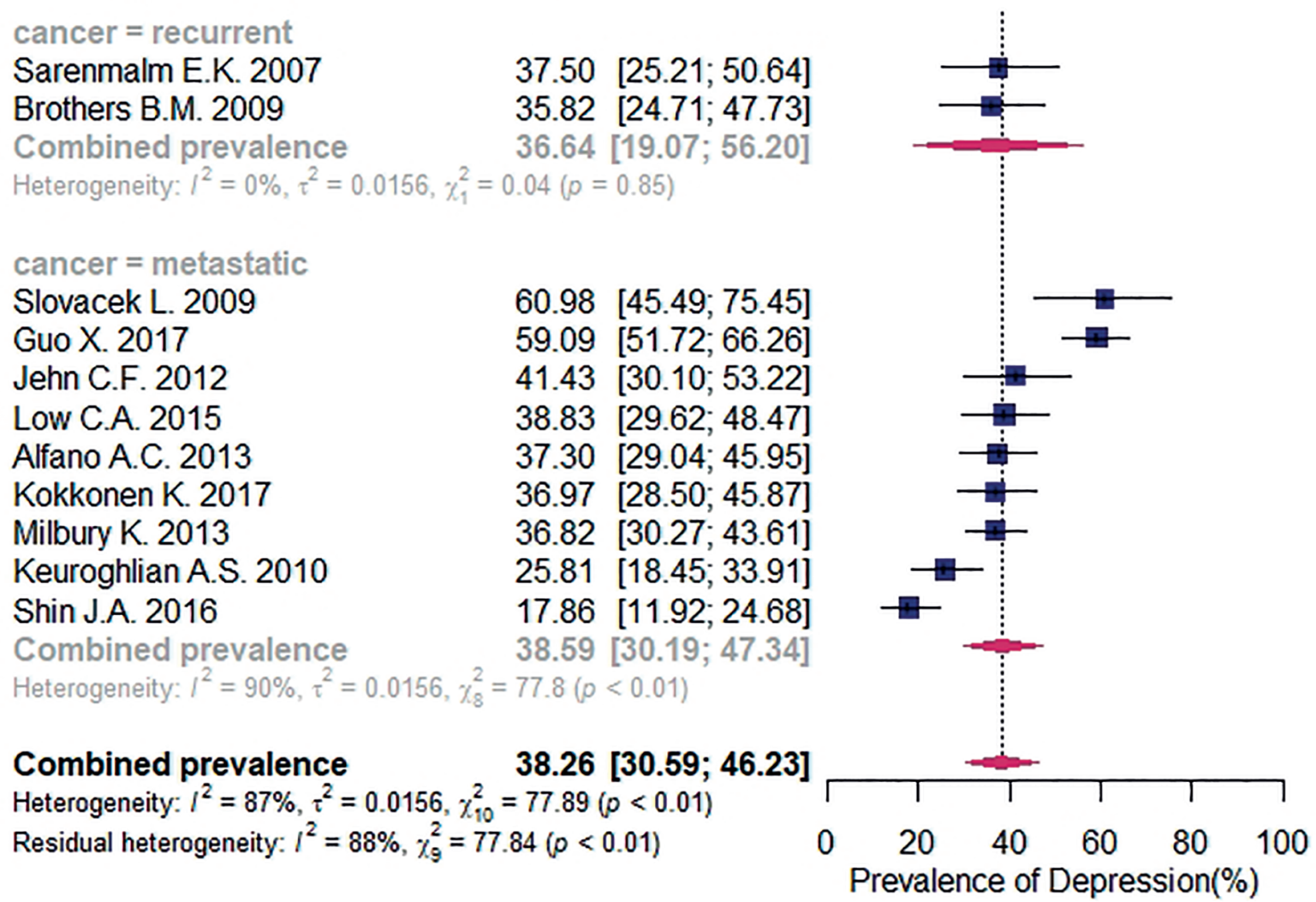

Fig. 3. Subgroup analysis of the depression prevalence based on the random-effects model among advanced breast cancer patients by cancer type. Abbreviations: C.I., confidence interval; $I^{2}$, percentage of variability in the effect sizes which is not caused by sampling error; $\tau^{2}$, between-study variance in the meta-analysis; $\chi 2$, (Q-statistic) difference between the observed effect sizes and the fixed-effect model estimate of the effect size.

\section{Pooled mean prevalence of mild, moderate and severe depression symptoms}

Based on the random-effects model, the pooled mean prevalence of mild, moderate, and severe depression symptoms was $38.23 \%$ (95\% CI [30.92; 45.83]). Test for heterogeneity suggests the presence of high heterogeneity: $\mathrm{I}^{2}=87 \%$; $\mathrm{Q}(\mathrm{df}=10)=77.89, \mathrm{p}$-value < 0.01 (Fig. 2).

According to the analysis that identifies the most influential studies, studentized residuals that are larger than "2" were identified in two studies, one with the lowest prevalence of depression symptoms of $17.86 \%{ }^{16}$, and one with high $59 \%$ prevalence of depression symptoms among 176 breast cancer patients ${ }^{17}$. When those studies were removed, the pooled mean prevalence of depression symptoms based on the random-effects model was slightly lower at 37.70\% (95\% CI [32.97; 42.54].

\section{Assessment of risk of bias across studies}

On the first funnel plot, four studies were located outside of the $95 \%$ CI limit lines, which is indicative of the high heterogeneity of the included studies. Visually we did not find clear evidence of the funnel plot asymmetry. The second plot also did not have clear evidence of the asymmetry. The Egger's unweighted regression tests for both plots were not statistically significant, and returned $z=1.01, p=0.31$, and $z=0.44, p=0.66$ respectively. Our findings suggest that the risk of publication bias across included studies was low.

\section{Sub-group analysis of studies that reported the number of patients with depression \\ Sub-group analyses based on the cancer type showed that the combined prevalence of depressiovn symptoms was almost the same between studies that focused on metastatic and recurrent breast cancer patients. The pooled prevalence of depression symp- toms in recurrent (local, regional or distant) breast cancer patients was 36.64\% (95\% CI [19.07; 56.20]; $\mathrm{I} 2=0 \% ; \mathrm{Q}(\mathrm{df}=1)=0.04 ; \mathrm{p}=0.85)$ and $38.59 \%(95 \%$ CI [30.19; 47.34]; I2=90\%; Q ( $d f=8)=77.8 ; p<0.01)$ in metastatic breast cancer patients (Fig. 3).}


Sub-group analysis based on the income level of the country where a study was conducted, showed that the pooled prevalence of depression symptoms in upper-middle income countries was higher than in high-income countries at $48.39 \%$ (95\% CI [32.31; 64.63]; $\left.\mathrm{I}^{2}=93 \% ; \mathrm{Q}(\mathrm{df}=1)=14.04 ; \mathrm{p}<0.01\right)$ and $35.79 \%$ (95\% CI [28.20; 43.74]; $I^{2}=80 \% ; \mathrm{Q}(\mathrm{df}=8)=39.36$; $\mathrm{p}<0.01)$ respectively.

Sub-group analysis based on the depression evaluation method showed that the pooled prevalence of depression symptoms among advanced breast cancer patients was the highest when reported with SDS scale at 59.56\% (95\% CI [51.92; 66.99], $\mathrm{I}^{2}=0 \%$; $\mathrm{Q}(\mathrm{df}=1)=0.04$; $\mathrm{p}=0.84$ ). Different cutoff points were used for the depression symptoms presence with the HADS questionnaire, three studies used " $\geq 8$ " and one study used " $\geq 7$ ".

\section{Meta-regression finding}

According to the meta-regression findings, the publication year, mean age of participants, marital status, and sample size did not significantly account for the heterogeneity in the effect sizes between studies.

\section{Discussion}

Depression is a common psychological comorbidity among advanced breast cancer patients, and the prevalence of depression symptoms varies from $17 \%$ to $61 \%$ according to the studies included in the present analysis. Advanced breast cancer patients have to deal with cancer recurrence or cancer progression beyond the primary location, which puts more pressure on their mental health. According to a meta-analysis of depression prevalence among breast cancer patients which included 44,075 patients, the global prevalence of depression was $32.2 \%$ (95\% CI $\left.[28.9,35.4] ; \mathrm{I}^{2}=99.1 \%\right)^{18}$. Based on the results of our meta-analysis, the prevalence of depression symptoms among 1223 advanced breast cancer patients was higher (38.23\%). This difference could be attributable to the specific focus of the present analysis on the advanced stage, methodological variations, and a smaller number of studies analyzed.

Among clinical factors that were explored as the potential sources of heterogeneity, the metastatic group had a higher prevalence of depression symptoms than the recurrent group, at $38.59 \%$ and $36.64 \%$, respectively. One of the factors that could contribute to this difference: recurrent breast cancer patients group included patients with local and regional recurrence, who generally has a more favorable 5-year survival rate.

The methodology of depression diagnosis has been a significant factor that could influence the number of diagnosed patients. Some studies show that the depression diagnosis rate was higher when self-assessment inventories were used compared to the structured interview results $s^{19,20,21}$, and the results of the present meta-analysis confirm those findings. Generally, most of the self-report depression scales were reported to be not designed to identify major depression or to be used as a diagnostic tool, but as a screening instrument ${ }^{22,23,24,25}$. Earlier findings suggest that HADS performance in detecting major depression was average but better than other conventional depression inventories ${ }^{22}$, which could justify our findings on its broad use in different countries.

Among sociodemographic factors that were explored as the potential sources of heterogeneity, we found that the upper-middle income countries had a higher prevalence of depression symptoms compared to the high-income countries, which is also in line with previously reported results ${ }^{18}$.

The limitations of the present systematic review and meta-analysis are the following: 1) Although formal tests to investigate possible bias across studies were not statistically significant, we acknowledge that we could not eliminate the publication bias, as we only included published studies in English. We attempted to lower the publication bias by following guidelines on the adequate literature review; 2) This is a meta-analysis of observational studies with their methodological limitations; 3) Studies from African, Eastern Mediterranean and South-East Asia regions did not met the inclusion criteria of the present meta-analysis; 4) We did not have enough data on the time between diagnosis of breast cancer to the time of the depression evaluation. 5) The heterogeneity of the included studies was high, although we excluded studies with stage III and stage IV breast cancer patients, if they did not define their stage III patients as recurrent ${ }^{26,27,28,29}$ or reported depression before recurrence ${ }^{30}$. We also excluded studies that reported results on the same group

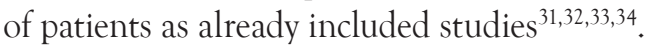

Clinical implications of our findings: the healthcare providers have to be prepared to have more than one-third of patients with breast cancer with psychological needs of various degrees not only at primary diagnosis but also afterward at recurrence and progression and beyond. According to a systematic review by Zainal and colleagues (2013), even among long-term breast cancer survivors the prevalence of depression goes up to $56 \%{ }^{35}$. It is important to improve psychological prevention methods to decrease the occurrence of depression, as breast cancer patients start receiving treatment from primary diagnosis and offer necessary evidence-based support and treatment to meet their psychological needs. For future research, our findings imply that there is a need to access what kind of psychological correction methods might be the most effective specifically among advanced breast 
cancer patients group to prevent the depression development and to help them manage their psychological burden through the entire treatment course.

\section{Conclusions}

Our results suggest that more than one-third of patients with metastatic and recurrent breast cancer are at risk of having various degrees of depression, which is consistent with previously reported results on the global depression prevalence among breast cancer patients. The high pooled prevalence of depression in this group indicates that those patients require adequate psychological support not only at the time of diagnosis, but throughout the entire course of their treatment.

\section{Author Contributions:}

I.K. conceived the original draft preparation. I.K., B.T., and F.B. were responsible for conception and design of the review. I.K., B.T., and F.B. were responsible for the data acquisition. I.K. and N.Z.Z. were responsible for the collection and assembly of the articles/published data, and their inclusion and interpretation in this review. I.K., B.T., N.Z.Z. and F.B. contributed equally to the present work. All authors contributed to the critical revision of the manuscript for valuable intellectual content. All authors have read and agreed with the final version of the manuscript.

\section{Compliance with Ethics Requirements:}

"The authors declare no conflict of interest regarding this article"

„The authors declare that all the procedures and experiments of this study respect the ethical standards in the Helsinki Declaration of 1975, as revised in 2008(5), as well as the national law."

"No funding for this study"

\section{Acknowledgements:}

None

\section{References}

1. Bray F, Ferlay J, Soerjomataram I, Siegel RL, Torre LA, Jemal A. Global cancer statistics 2018: GLOBOCAN estimates of incidence and mortality worldwide for 36 cancers in 185 countries. CA Cancer J Clin. 2018;68(6):394-424.

2. Maajani K, Jalali A, Alipour S, Khodadost M, Tohidinik HR, Yazdani K. The global and regional survival rate of women with breast cancer: a systematic review and meta-analysis. Clin Breast Cancer. 2019;19(3):165-77.

3. Colleoni M, Sun Z, Price KN, et al. Annual hazard rates of recurrence for breast cancer during 24 years of follow-up: results from the International Breast Cancer Study Group Trials I to V. J Clin Oncol. 2016;34(9):927-35.
4. Santiago RJ, Wu L, Harris E, et al. Fifteen-year results of breast-conserving surgery and definitive irradiation for Stage I and II breast carcinoma: the University of Pennsylvania experience. Int J Radiat Oncol Biol Phys. 2004;58(1):233-40.

5. Saphner T, Tormey DC, Gray R. Annual hazard rates of recurrence for breast cancer after primary therapy. J Clin Oncol. 1996;14(10):2738-46.

6. Voogd AC, Nielsen M, Peterse JL, et al. Differences in risk factors for local and distant recurrence after breast-conserving therapy or mastectomy for stage I and II breast cancer: pooled results of two large European randomized trials. J Clin Oncol. 2001;19(6):1688-97.

7. Oh S, Heflin L, Meyerowitz BE, Desmond KA, Rowland JH, Ganz PA. Quality of life of breast cancer survivors after a recurrence: a follow-up study. Breast Cancer Res Treat. 2004;87(1):45-57.

8. Ganz PA, Desmond KA, Leedham B, Rowland JH, Meyerowitz BE, Belin TR. Quality of life in long-term, disease-free survivors of breast cancer: a follow-up study. J Natl Cancer Inst. 2002;94(1):39-49.

9. Schunkert EM, Zhao W, Zänker K. Breast cancer recurrence risk assessment: is non-invasive monitoring an option? Biomed Hub. 2018;3(3):1-17.

10. American Cancer Society. Breast Cancer Facts \& Figures 2019-2020. Atlanta; 2019. Available from: https:// www.cancer.org/content/dam/cancer-org/research/cancer-facts-and-statistics/breast-cancer-facts-and-figures/ breast-cancer-facts-and-figures-2019-2020.pdf (Accessed on May 21, 2020)

11. Budhwani S, Moineddin R, Wodchis WP, Zimmermann C, Howell D. Do longitudinally collected symptom scores predict time to death in advanced breast cancer: a joint modeling analysis. J Pain Symptom Manag. 2019; Available from: http://www.sciencedirect.com/science/article/pii/ S0885392419307092

12. Giese-Davis J, Collie K, Rancourt KMS, Neri E, Kraemer $\mathrm{HC}$, Spiegel D. Decrease in depression symptoms is associated with longer survival in patients with metastatic breast cancer: a secondary analysis. J Clin Oncol. 2011;29(4):413-20.

13. Adjei Boakye E, Osazuwa-Peters N, Mohammed KA, et al. Prevalence and factors associated with diagnosed depression among hospitalized cancer patients with metastatic disease. Soc Psychiatry Psychiatr Epidemiol. 2020;55(1):15-23.

14. Liberati A, Altman DG, Tetzlaff J, et al. The PRISMA statement for reporting systematic reviews and meta-analyses of studies that evaluate healthcare interventions: explanation and elaboration. BMJ. 2009;339:b2700.

15. Hoy D, Brooks P, Woolf A, et al. Assessing risk of bias in prevalence studies: modification of an existing tool and evidence of interrater agreement. J Clin Epidemiol. 2012;65(9):934-9.

16. Shin JA, El-Jawahri A, Parkes A, Schleicher SM, Knight HP, Temel JS. Quality of life, mood, and prognostic understanding in patients with metastatic breast cancer. J Palliat Med. 2016;19(8):863-9.

17. Guo X, Xu J, E Y, Yu Z, Sun T. Correlation between hormone receptor status and depressive symptoms in patients with metastatic breast cancer. Oncotarget. 2017;8(31):50774-81.

18. Pilevarzadeh M, Amirshahi M, Afsargharehbagh R, Rafiemanesh H, Hashemi S-M, Balouchi A. Global prevalence of depression among breast cancer patients: a systematic review and meta-analysis. Breast Cancer Res Treat. 2019;176(3):519-33.

19. Hopwood CJ, Morey LC, Edelen MO, et al. A comparison of interview and self-report methods for the assessment 
of borderline personality disorder criteria. Psychological Assessment. 2008; 20(1): 81-5.

20. Stuart A, Pasco J, Jacka F, Brennan S, Berk M, Williams L. Comparison of self-report and structured clinical interview in the identification of depression. Compr Psychiatry. 2014; 55: 866-9.

21. Mitchell AJ, Chan M, Bhatti H, et al. Prevalence of depression, anxiety, and adjustment disorder in oncological, haematological, and palliative-care settings: A meta-analysis of 94 interview-based studies. Lancet Oncol. 2011;12(2):160-74.

22. Mitchell AJ, Meader N, Symonds P. Diagnostic validity of the Hospital Anxiety and Depression Scale (HADS) in cancer and palliative settings: a meta-analysis. J Affect Disord. 2010;126(3):335-48.

23. Wang G, Hsu S, Feng A, et al. The HADS and the DT for screening psychosocial distress of cancer patients in Taiwan. Psycho-oncology. 2011;20(6):639-46.

24. Warmenhoven F, van Rijswijk E, Engels Y, et al. The Beck Depression Inventory (BDI-II) and a single screening question as screening tools for depressive disorder in Dutch advanced cancer patients. Support Care Cancer. 2012;20(2):319-24.

25. Hann D, Winter K, Jacobsen P. Measurement of depressive symptoms in cancer patients: evaluation of the Center for Epidemiological Studies Depression Scale (CES-D). J Psychosom Res. 1999;46(5):437-43.

26. Hamash KI, Umberger W, Aktas A, Walsh D, Cheruvu VK. The effect of the pain symptom cluster on performance in women diagnosed with advanced breast cancer: the mediating role of the psychoneurological symptom cluster. Pain Manag Nurs. 2018;19(6):627-36.

27. Au A, Lam W, Tsang J, et al. Supportive care needs in Hong Kong Chinese women confronting advanced breast cancer. Psychooncology. 2013;22(5):1144-51.

28. Valderrama Rios MC, Sanchez Pedraza R, Rios MCV, Pedraza RS. Anxiety and depression disorders in relation to the quality of life of breast cancer patients with locally advanced or disseminated stage. Rev Colomb Psiquiatr (English ed). 2018;47(4):211-20.

29. Akechi T, Nakano T, Okamura H, et al. Association between self-reported sleep disturbance and other symptoms in patients with advanced cancer. Support Care Cancer. 2018;14(5):549-55.

30. Thornton LM, Andersen BL, Carson WE 3rd. Immune, endocrine, and behavioral precursors to breast cancer recurrence: a case-control analysis. Cancer Immunol Immunother. 2008;57(10):1471-81.
31. Badr H, Milbury K. Associations between depression, pain behaviors, and partner responses to pain in metastatic breast cancer. Pain. 2011;152(11):2596-604.

32. Slovacek L, Slovackova B, Slanska I, Petera J, Priester P. Quality of life and depression among metastatic breast cancer patients. Med Oncol. 2010;27(3):958-9.

33. Kenne Sarenmalm E, Ohlén J, Odén A, Gaston-Johansson F. Experience and predictors of symptoms, distress and health-related quality of life over time in postmenopausal women with recurrent breast cancer. Psychooncology. 2008;17(5):497-505.

34. Badr H, Shen MJ. Pain catastrophizing, pain intensity, and dyadic adjustment influence patient and partner depression in metastatic breast cancer. Clin J Pain. 2014;30(11):923-33.

35. Zainal NZ, Nik-Jaafar NR, Baharudin A, Sabki ZA, Ng CG. Prevalence of depression in breast cancer survivors: a systematic review of observational studies. Asian Pacific J Cancer Prev. 2013;14(4):2649-56.

36. Alfano ACC, Paiva CE, Rugno FC, da Silva RH, Paiva BSR. Biologically based therapies are commonly self-prescribed by Brazilian women for the treatment of advanced breast cancer or its symptoms. Support Care Cancer. 2014;22(5):130311.

37. Brothers BM, Andersen BL. Hopelessness as a predictor of depressive symptoms for breast cancer patients coping with recurrence. Psychooncology. 2009;18(3):267-75.

38. Keuroghlian AS, Butler LD, Neri E, Spiegel D. Hypnotizability, posttraumatic stress, and depressive symptoms in metastatic breast cancer. Int J Clin Exp Hypn. 2010;58(1):39-52.

39. Kokkonen K, Saarto T, Makinen T, et al. The functional capacity and quality of life of women with advanced breast cancer. Breast Cancer. 2017;24(1):128-36.

40. Low CA, Stanton AL. Activity disruption and depressive symptoms in women living with metastatic breast cancer. Health Psychology. 2015;34(1): 89-92.

41. Milbury K, Badr H. Sexual problems, communication patterns, and depressive symptoms in couples coping with metastatic breast cancer. Psychooncology. 2013;22(4):814-22.

42. Kenne Sarenmalm E, Öhlén J, Jonsson T, Gaston-Johansson F. Coping with recurrent breast cancer: predictors of distressing symptoms and health-related quality of life. J Pain Symptom Manag. 2007;34(1):24-39.

43. Slovacek L, Slovackova B, Slanska I, et al. Depression symptoms and health-related quality of life among patients with metastatic breast cancer in programme of palliative cancer care. Neoplasma. 2009;56(6):467-72. 


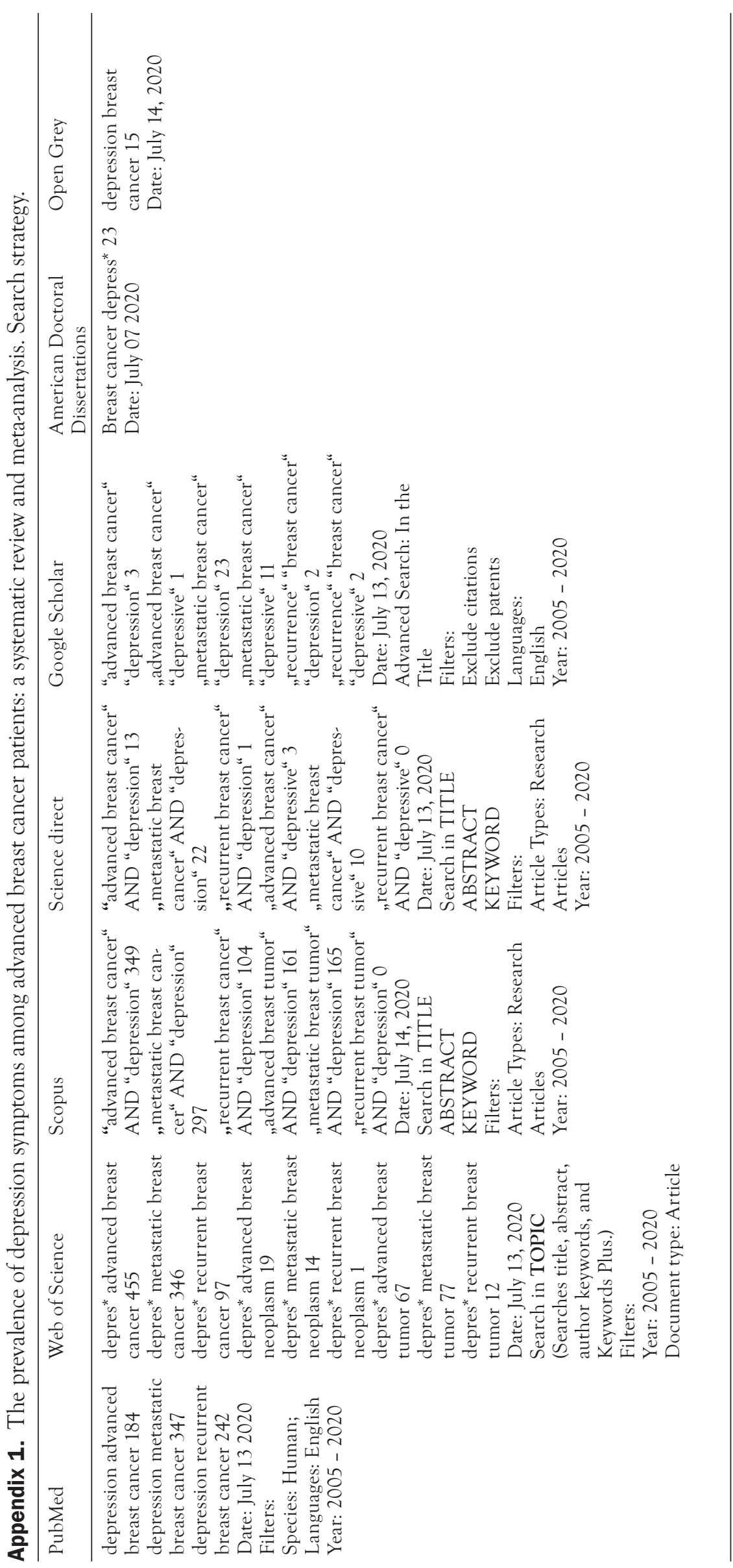

